Pacific Journal of Mathematics

CHEBYSHEV CENTERS IN SPACES OF CONTINUOUS 


\title{
CHEBYSHEV CENTERS IN SPACES OF CONTINUOUS FUNCTIONS
}

\author{
JOSEPH D. WARD
}

\begin{abstract}
A bounded set $F$ in a Banach space $X$ has a Chebyshev center if there exists in $X$ a "smallest" ball containing $F$. A Banach space $X$ is said to admit centers if every bounded subset of $X$ has a center. The purpose of this paper is to show that certain spaces of continuous functions admit centers.
\end{abstract}

1. Introduction. Let $X$ be a real normed linear space, $G$ a subset of $X$ and $f$ an element of $X$. Then a best approximant, $g_{*}$, to $f$ from $G$ (if it exists) is a solution to

$$
\inf \{\|g-f\|, g \in G\} \text {. }
$$

It may happen that $f$ is not defined exactly but is known to lie in a bounded set $F$. It is reasonable then to approximate simultaneously all $f \in F$ by solving

$$
\inf \sup \{\|g-f\|, f \in F\} \equiv R_{G}(F)
$$

where the inf is taken over all $g \in G$. Thus we may view problem (1.2) as a natural generalization of the best approximation problem (1.1). If $G=X$ then the solutions of (1.2) are called Chebyshev centers of $F$, following Garkavi [2]. In [3], Kadets and Zamyatin showed that $C([a, b], R)$, the space of real-valued continuous functions on $[a, b]$, admits centers. This means that (1.2) has a solution in $C([a, b], R)$ for $F$ an arbitrary bounded set in $C([a, b], R)$.

The purpose of this note is to show that the Kadets-Zamyatin result holds under much greater generality. Let

$$
\begin{aligned}
\Omega & =\text { a paracompact Hausdorff space } \\
S & =\text { a normal space } \\
C(A, B) & =\text { space of continuous functions from } A \text { to } B .
\end{aligned}
$$

Our main theorems are:

Theorem 1. $C(\Omega, X)$ admits centers if $X$ is a finite dimensional, rotund space.

TheOREM 2. $C(S, H)$ admits centers if $H$ is an arbitrary Hilbert space.

2. Proof of Theorem 1 . 
Definition 2.1. Let $X$ and $E$ be Banach spaces and $F: X \rightarrow 2^{E}$. $F$ is said to be upper semi-continuous (u.s.c) if the set $\{x \mid F(x) \subset G\}$ is open in $X$ for every open $G \subset E . \quad F$ is said to be lower semicontinuous (l.s.c) if the set $\{x \mid F(x) \cap G\}$ is open in $X$ for every open $G \subset E$.

Proof of Theorem 1. We use the following notation:

$F=$ fixed but arbitrary bounded set in $C(\Omega, X)$

$\mathscr{N}(t)=$ the directed family of open $t$-neighborhoods, $t \in \Omega$

$\Omega(t, N)=\bigcup\{f(s)\}$ where $f \in F, s \in N$

$A_{N}(t)=$ convex closure of $\Omega(t, N)$

$B(x, K)=$ ball of radius $K$ centered at $x$

$R(F)=$ Chebyshev radius of $F$ with respect to $C(\Omega, X)$ as defined in (1.2).

Suppose $F$ is bounded by $K$. Now for each $t \in \Omega$, consider the net $N \rightarrow A_{N}(t)$ defined on $\mathscr{N}(t)$. The range of this net lies in the metric space $\mathscr{F}(B(0, K))$ whose elements are the compact, convex and nonempty subsets of $B(0, K)$. We put

$$
A(t)=\lim A_{N}(t), N \in \mathscr{N}(t) .
$$

This limit exists in $\mathscr{F}(B(0, K))$ by virtue of the compactness of this space and the monotonicity of the net $\left\{A_{N}(t)\right\}, N \in \mathscr{N}(t)$. It may be verified that

$$
A(t)=\bigcap A_{N}(t), N \in \mathscr{N}^{-}(t) .
$$

We show that the map $A: \Omega \rightarrow \mathscr{F}(B(0, K))$ is u.s.c. . This requires us to choose any nonempty open set $G \subset X$ and then show that $\{t \in \Omega: A(t) \subset G\}$ is open in $\Omega$. Let $t_{0}$ belong to this set. Then by (2.2), there is an $N \in \mathscr{N}\left(t_{0}\right)$ for which $A_{N}\left(t_{0}\right) \subset G$. Hence, if $t \in N$, we have by (2.3) that

$$
A(t) \subset A_{N}(t)=A_{N}\left(t_{0}\right) \subset G
$$

and so $A$ is upper semi-continuous.

Let $R_{X}(A)=\sup \left\{R_{X}(A(t)): t \in \Omega\right\}$. Following Olech [4], we introduce the map $G: \Omega \rightarrow 2^{X}$ defined by

$$
G(t)=\left\{\beta \in X: A(t) \subset B\left(\beta, R_{X}(A)\right)\right\} .
$$

Olech proved (under the assumption that $X$ is uniformly rotund which is the same as rotund in finite dimensions) that the values $G(t)$ are compact, convex and nonempty subsets of $X$ and $G$ is lower semi-continuous in $t$. Thus by appealing to the Michael selection theorem, 
there is a continuous selection $f$ for $G$.

It is clear that $\|f-g\| \leqq R_{X}(A)$ for all $g \in F$. It remains to show that $R_{X}(A) \leqq R\left(F^{\prime}\right)$. Let $\varepsilon$ be arbitrary and choose $t \in \Omega$ so that $R_{X}(A(t))>R_{X}(A)-\varepsilon$. Since $f \in C(\Omega, X)$, we may choose $N \in \mathscr{N}(t)$ for which osc $(f: N)<\varepsilon$. Due to (2.2) and (2.3) we may assume that $N$ has been chosen so "small" that there is a $\gamma \in N$ and $g \in F$ for which $R_{X}(A)-2 \varepsilon<|g(\gamma)-f(\gamma)| \leqq R(F)$.

3. Proof of Theorem 2. The problem with $X$ being infinite dimensional is that we have no right to expect $\lim A_{N}(t), N \in \mathscr{N}(t)$, to exist as in Theorem 1. Thus the method of proof of Theorem 1 must be abandoned. Nevertheless, Theorem 2 may still be proved.

Proof of Theorem 2. Let $F \subset C(S, H)$ be bounded by $K$. There exist "approximate centers", call then $f_{n}$, such that $f_{n}$ is within $R(F)+1 / n$ of each element of $F$. We clearly have for any approximate center $f_{i}$ and $f_{j}$ the relationship $\left\|f_{i}-f_{j}\right\| \leqq 4 K$.

Step 1. We show that for arbitrary $\delta>0$, there exists an $\varepsilon_{\delta}>$ 0 such that for any $\left(R(F)+\varepsilon_{\delta}\right)$-approximate center $f_{1}$, we may construct an $\left(R(F)+\varepsilon_{\delta / 2}\right)$-center $f_{2}$ such that $f_{2} \in B\left(f_{1}, \delta\right)$.

Proof of Step 1. Pick $\varepsilon_{\hat{\delta}}>0$ so that $\delta=\left(2 \varepsilon_{\delta} R(F)+\varepsilon_{\hat{\delta}}^{2}\right)^{1 / 2}$. Pick $g$ where $g$ is an $\left(R(F)+\varepsilon_{\delta / 2}\right)$-approximate center for $F$. It is clear that $\left\|g-f_{1}\right\| \leqq 4 K$. Let $F(t)=\left\{f(t): f \in F^{\prime}\right\}$. By definition of approximate center, for all $t \in S$,

$$
B\left(f_{1}(t), R(F)+\varepsilon_{\delta}\right) \cap B\left(g(t), R(F)+\varepsilon_{\delta / 2}\right) \supset F(t) .
$$

For convenience sake set

$$
\begin{aligned}
r_{1} & =R(F)+\varepsilon_{\tilde{\delta}} ; r_{2}=R(F)+\varepsilon_{\delta / 2} \\
d(t) & =\left\|f_{1}(t)-g(t)\right\| .
\end{aligned}
$$

Define

$$
f_{2}(t)=f_{1}(t)+\beta(t)\left(g(t)-f_{1}(t)\right)
$$

where

$$
\beta(t)=\left\{\begin{array}{lll}
1 & \text { if } & \left(r_{1}^{2}-r_{2}^{2}\right) / d^{2} \geqq 1 \\
\left(\left(r_{1}^{2}-r_{2}^{2}\right) / d^{2}\right)^{1 / 2} & \text { if } \quad\left(r_{1}^{2}-r_{2}^{2}\right) / d^{2}<1
\end{array}\right.
$$

Note that $0 \leqq \beta(t) \leqq 1$ for all $t \in S$. We now make three claims about $f_{2}$.

(1) $f_{2}$ is a continuous function, i.e., $f_{2} \in C(S, H)$ 
(2) $\left\|f_{2}-f_{1}\right\| \leqq\left(2 \varepsilon_{\delta} R(F)+\varepsilon_{\delta}^{2}\right)^{1 / 2} \leqq \delta$

(3) $f_{2}$ is an $\left(R(F)+\varepsilon_{\delta / 2}\right)$-approximate center of $F$

Proof of (1). Since $g$ and $f_{1}$ are continuous functions and $d(t)=$ $\left\|f_{1}(t)-f_{2}(t)\right\|$ is continuous, $\beta(t)$ is also continuous. This clearly implies the continuity of $f_{2}$.

Proof of (2). It suffices to show that $\left\|f_{2}(t)-f_{1}(t)\right\| \leqq\left(2 \varepsilon_{\delta} R(F)+\right.$ $\left.\varepsilon_{\delta}^{2}\right)^{1 / 2} \leqq \delta$ for all $t \in S$. Thus for fixed $t_{0},\left\|f_{2}\left(t_{0}\right)-f_{1}\left(t_{0}\right)\right\|=\| \beta\left(t_{0}\right)\left(g\left(t_{0}\right)-\right.$ $\left.f_{1}\left(t_{0}\right)\right) \|$. If $\beta\left(t_{0}\right)=1, r_{1}^{2}-r_{2}^{2} \geqq d^{2}$ so

$$
\begin{aligned}
& \left\|\beta\left(t_{0}\right)\left(g\left(t_{0}\right)-f_{1}\left(t_{0}\right)\right)\right\|=\left\|g\left(t_{0}\right)-f_{1}\left(t_{0}\right)\right\|=d\left(t_{0}\right) \\
& \quad \leqq\left(r_{1}^{2}-r_{2}^{2}\right)^{1 / 2} \leqq \delta .
\end{aligned}
$$

If $\beta\left(t_{0}\right)<1$,

$$
\begin{aligned}
\left\|f_{2}\left(t_{0}\right)-f_{1}\left(t_{0}\right)\right\|^{2} & =\left\|\beta\left(t_{0}\right)\left(f_{2}\left(t_{0}\right)-f_{1}\left(t_{0}\right)\right)\right\|^{2} \\
& =\left(\left(r_{1}^{2}-r_{2}^{2}\right) / d^{2}\right) d^{2}=r_{1}^{2}-r_{2}^{2}
\end{aligned}
$$

so $\left\|f_{2}\left(t_{0}\right)-f_{1}\left(t_{0}\right)\right\| \leqq\left(r_{1}^{2}-r_{2}^{2}\right)^{1 / 2} \leqq \delta$. This proves (2).

Proof of (3). Since by (1) $f_{2} \in C(S, H)$, it suffices to show that for each $t_{0} \in S$,

$$
\begin{aligned}
& B\left(f_{2}\left(t_{0}\right), R(F)+\varepsilon_{\delta / 2}\right) \\
& \quad \supset B\left(f_{1}\left(t_{0}\right), R(F)+\varepsilon_{\delta}\right) \cap B\left(g\left(t_{0}\right), R(F)+\varepsilon_{\delta / 2}\right) \supset F\left(t_{0}\right) .
\end{aligned}
$$

The above is equivalent to showing that for all $x$ such that $\left\|x-f_{1}\right\| \leqq r_{1}$ and $\|x-g\| \leqq r_{2}$, then $\left\|x-f_{2}\right\| \leqq r_{2}$.

Without loss of generality assume $f_{1}$ is 0 . The above problem then simplifies to showing that the implication $\|x\| \leqq r_{1}$ and $\|x-g\| \leqq$ $r_{2}$, then $\left\|x-f_{2}\right\| \leqq r_{2}$ holds for all $x \in V$ and for all $V \subset H$ where $V$ is a two dimensional subspace containing $g$. Hence we are reduced to a problem in two dimensional Hilbert space and a few simple applications of the Pythagorean theorem prove the assertion.

Step 2. Let $f_{1}$ be any $\left(R(F)+\varepsilon_{\delta_{1}}\right)$-approximate center of $F$. Having defined $f_{n}$, take $f_{n+1}$ to be an $\left(R(F)+\varepsilon_{\delta_{n+1}}\right)$-approximate center such that $f_{n+1} \in B\left(f_{n}, \delta_{n}\right)$ and $\delta_{n+1}=\delta_{n} / 2$, which we may do by Step 1. Evidently $\varepsilon_{\delta_{n}} \rightarrow 0$ as $n \rightarrow \infty$.

Now consider $\left\{f_{n}\right\}_{n=1}^{\infty}$. For all $i, j \geqq K,\left\|f_{i}-f_{j}\right\| \leqq\left\|f_{i}-f_{K}\right\|+$ $\left\|f_{K}-f_{j}\right\| \leqq 2 \sum_{n=K}^{\infty} \delta_{1} / 2^{n}=\delta_{1} / 2^{K-1}$. So $\left\{f_{n}\right\}_{n=1}^{\infty}$ is a uniformly convergent sequence with limit point $f^{\prime}, f^{\prime} \in C(S, H)$. Also for each $g \in F$,

$$
\begin{aligned}
& \left.\sup \left\{\left\|g-f^{\prime}\right\|, g \in F\right\} \leqq \sup \left\{\left\|g-f_{n}\right\|+\left\|f_{n}-f^{\prime}\right\|\right), g \in F\right\} \\
& \quad \leqq R(F)+\varepsilon_{\delta_{n}}+\gamma_{n}
\end{aligned}
$$


where $\gamma_{n}$ is a null sequence. Hence $\sup \left\{\left\|g-f^{\prime}\right\|, g \in F\right\}=R(F)$ and $f^{\prime}$ is a Chebyshev center of $F$.

REMARK 1. Since paracompact spaces are normal [1], Theorem 2 generalizes Theorem 1 in the case that the range space of the space of continuous functions is a finite dimensional Hilbert space.

REMARK 2. This author was unable to resolve the question whether Theorem 2 holds when the range space of $C(S, H)$ is an arbitrary uniformly convex space.

The author thanks the referee whose suggestions simplified the proof of Theorem 2.

\section{REFERENCES}

1. J. Dugundji, Topology, Allyn and Bacon, Inc., Boston, 1966.

2. A. L. Garkavi, The best possible net and the best possible cross-section of a set in a normed space, Izv. Akad. Nauk. SSSR, 26 (1962), 87-106. (Russian) (Translated in Amer. Math. Soc. Trans., Ser. 2, 39 (1964)).

3. I. M. Kadets and V. Zamyatin, Chebyshev centers in the space $C[a, b]$, Teo. Funk., Funkcion. Anal. Pril., 7 (1968), 20-26. (Russian).

4. C. Olech, Approximation of set-valued functions by continuous functions, Coll. Math., 19 (1968), 285-293.

Received October 9, 1973 and in revised form January 22, 1974. This research comprised a part of the author's $\mathrm{Ph}$. D. thesis at Purdue University. The author wishes to express his gratitude to his advisor, Professor Richard Holmes, for numerous illuminating discussions.

PuRdue UnIVersity

Current address: Texas A \& M University

College Station, Texas 77843 



\section{PACIFIC JOURNAL OF MATHEMATICS}

EDITORS

RICHARD ARENS (Managing Editor)

University of California

Los Angeles, California 90024

R. A. Beaumont

University of Washington

Seattle, Washington 98105

J. DugundJI

Department of Mathematics

University of Southern California

Los Angeles, California 90007

D. Gilbarg and J. Milgram

Stanford University

Stanford, California 94305

\section{ASSOCIATE EDITORS}

E. F. BECKENBACH

B. H. NeumanN

F. WOLF

K. YOSHIDA

\section{SUPPORTING INSTITUTIONS}

UNIVERSITY OF BRITISH COLUMBIA CALIFORNIA INSTITUTE OF TECHNOLOGY

UNIVERSITY OF CALIFORNIA

MONTANA STATE UNIVERSITY

UNIVERSITY OF NEVADA

NEW MEXICO STATE UNIVERSITY

OREGON STATE UNIVERSITY

UNIVERSITY OF OREGON

OSAKA UNIVERSITY

\author{
UNIVERSITY OF SOUTHERN CALIFORNIA \\ STANFORD UNIVERSITY \\ UNIVERSITY OF TOKYO \\ UNIVERSITY OF UTAH \\ WASHINGTON STATE UNIVERSITY \\ UNIVERSITY OF WASHINGTON \\ $\stackrel{*}{*} \stackrel{*}{*}{ }^{*}{ }^{*}{ }^{2}$ AMERICAN MATHEMATICAL SOCIETY \\ NAVAL WEAPONS CENTER
}




\section{Pacific Journal of Mathematics}

\section{Vol. 52, No. $1 \quad$ January, 1974}

David R. Adams, On the exceptional sets for spaces of potentials ............ 1

Philip Bacon, Axioms for the Čech cohomology of paracompacta ............ 7

Selwyn Ross Caradus, Perturbation theory for generalized Fredholm operators ..... 11

Kuang-Ho Chen, Phragmén-Lindelöf type theorems for a system of nonhomogeneous equations ............................ 17

Frederick Knowles Dashiell, Jr., Isomorphism problems for the Baire classes .......

M. G. Deshpande and V. K. Deshpande, Rings whose proper homomorphic images are right subdirectly irreducible . . . . . . . . . . . . . . . . . . . . . . . . .

Mary Rodriguez Embry, Self adjoint strictly cyclic operator algebras .............

Paul Erdős, On the distribution of numbers of the form $\sigma(n) / n$ and on some related

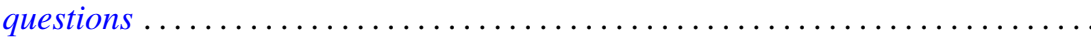

Richard Joseph Fleming and James E. Jamison, Hermitian and adjoint abelian

operators on certain Banach spaces ............................

Stanley P. Gudder and L. Haskins, The center of a poset .................. 85

Richard Howard Herman, Automorphism groups of operator algebras . . . ........

Worthen N. Hunsacker and Somashekhar Amrith Naimpally, Local compactness of families of continuous point-compact relations ....................

Donald Gordon James, On the normal subgroups of integral orthogonal groups ....

Eugene Carlyle Johnsen and Thomas Frederick Storer, Combinatorial structures in

loops. II. Commutative inverse property cyclic neofields of prime-power

order.

Ka-Sing Lau, Extreme operators on Choquet simplexes . . . . . . . . . . . . . . 129

Philip A. Leonard and Kenneth S. Williams, The septic character of 2, 3, 5 and $7 \ldots 143$

Dennis McGavran and Jingyal Pak, On the Nielsen number of a fiber map ........ 149

Stuart Edward Mills, Normed Köthe spaces as intermediate spaces of $L_{1}$ and

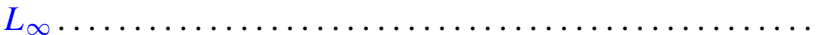

Philip Olin, Free products and elementary equivalence. .

Louis Jackson Ratliff, Jr., Locally quasi-unmixed Noetherian rings and ideals of the principal class.

Seiya Sasao, Homotopy types of spherical fibre spaces over spheres ...

Helga Schirmer, Fixed point sets of polyhedra ...

Kevin James Sharpe, Compatible topologies and continuous irreducible

representations.

Frank Siwiec, On defining a space by a weak base . . . . . . . . . . . . . . . 233

James McLean Sloss, Global reflection for a class of simple closed curves ....... 247

M. V. Subba Rao, On two congruences for primality . .

Raymond D. Terry, Oscillatory properties of a delay differential equation of even

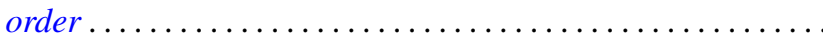

Joseph Dinneen Ward, Chebyshev centers in spaces of continuous functions . .

Robert Breckenridge Warfield, Jr., The uniqueness of elongations of Abelian

groups...

V. M. Warfield, Existence and adjoint theorems for linear stochastic differential

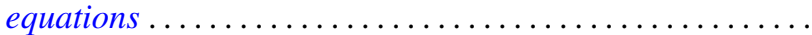

